\title{
İstanbul’a Yönelik İç Göçün Analizi: Çekim Modeli Yaklaşımı*
}

\author{
Halil İbrahim KESKIN**
}

$\ddot{\mathbf{O z}}$

İstanbul, geçmiște olduğu gibi günümüzde de önemli bir çekim merkezidir. Ancak, son yıllarda İstanbul'a olan iç göçün azaldığı görülmektedir. Çalışmalar, göç literatürü tarafından ortaya konulan benzer ekonomik ve sosyal faktörlerin Türkiye için geçerli olduğunu gösterse de, bu faktörlerin uygun tekniklerle ile araştırlması noktasında şüpheler bulunmaktadır. İç göçü araştırmak için kullanılan çekim modeli logaritmik doğrusal bir modeldir. Yapılan bazı çalışmalar logaritmik dönüşümün teorik olarak bazı sorunlara neden olduğunu ortaya koymuştur. Bu sorunlar geleneksel tahmin yöntemleriyle düzeltilememektedir. Dolayısıyla bu sorunun üstesinden gelmek için Poisson tahmincilerinin kullanılması önerilmektedir. Bu çalışmada çeşitli tahmin teknikleri yardımıyla İstanbul'a yönelik iç göçün araștırılması amaçlanmaktadır. Elde edilen bulgular PPML tahmincisinin geleneksel en küçük kareler ve panel tahmincilerine göre, çekim modelinin tahmini için daha uygun olduğunu göstermektedir. Standart yöntemlerle elde edilen sonuçlar göreli işsizlik faktörünün İstanbul'a yönelik göçü anlamlı bir şekilde arttırdığını gösterirken, PPML sonuçları göreli işsizliğin İstanbul'a yönelik iç göçü açıklamada anlamlı bir etkiye sahip olmadığını göstermektedir.

Anahtar Kelimeler: İç göç, Çekim Modeli, PPML, Panel Veri Analizi, İşgücü Piyasası, İstanbul

\section{Analysis of Internal Migration to Istanbul: Gravity Model Approach}

\section{Abstract}

Istanbul, as it was in the past, is still an important magnet for immigrants. However, it is seen that the internal migration to Istanbul has decreased in recent years. Even though the studies show similar economic and social factors-put forth by migration literature are valid for Turkey, there are doubts about whether these factors are being investigated with appropriate techniques. The gravity model that is used for investigating internal migration is a logarithmic linear model. Some studies have revealed that the logarithmic transformation causes some problems in theoretically. These problems cannot be solved by conventional estimation methods. Therefore, it is

\section{Özgün Araştırma Makalesi (Original Research Article)}

Geliș/Received: 30.05 .2019

Kabul/Accepted: 26.10 .2019

DOI: http://dx.doi.org/10.17336/igusbd.571951

* Bu çalışma 17-19 Nisan 2019 tarihinde İstanbul'da düzenlenen GELIŞ̧íM-UWE 2019: 3.

Uluslararası Ekonomi, Finans ve Yönetim Konferansı'nda sözlü bildiri olarak sunulmuştur.

** Dr., Çukurova Üniversitesi, İktisadi İdari Bilimler Fakültesi. Ekonometri Bölümü, Adana, Türkiye,

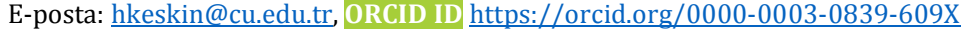


recommended to use Poisson estimators for overcoming this problem. The aim of this study is to investigate the internal migration to Istanbul with the help of various estimation techniques. The findings show that the PPML estimator is a more proper method to estimate the gravity model than the traditional least squares and panel estimators. While the results obtained by standard methods showed that the relative unemployment factor significantly increased the migration to Istanbul, the PPML results show that the relative unemployment did not have a significant effect on the explanation of the internal migration to Istanbul.

Keywords: Internal Migration, Gravity Model, PPML, Panel Data Analysis, Labor Market, Istanbul

\section{Giriș}

İstanbul geçmişte olduğu gibi günümüzde de önemli bir çekim merkezidir. İstanbul'a yönelik iç göçün araştırıldığı birçok çalışma bulunmaktadır. Bu çalıșmaların bazıları uluslararası literatür tarafından ortaya konulan ekonomik, sosyal, kültürel ve güvenlik gibi göçü etkileyen dinamiklerin Türkiye'deki iç göç için de geçerli faktörler olduğunu belirtirken, diğer çalışmalar bunların dışında, başka faktörlerin de iç göçü açıkladığına işaret etmektedir. Ancak bu alanda yapılan son çalışmalar, göçü etkileyen dinamiklerin Türkiye'nin her bir bölgesinde farklılık gösterdiğini belirtmekle birlikte, Türkiye'de iç göçe neden olan geleneksel dinamiklerin hala literatürde kabul gören benzer ekonomik ve sosyal faktörler olduğunu belirtmektedir (Akarca \& Tansel, 2018, s.122). İstanbul'da istihdam alanlarının yoğun olarak bulunmasının yanında, İstanbul yüksek kentleşme oranına bağlı olarak birçok avantajlar sunması bakımından Türkiye'de iç göç alan en önemli merkezdir. Türkiye İstatistik Kurumunun verileri 2016 yılında neredeyse 15 milyona ulaşan İstanbul nüfusunun yaklaşık yarısının İstanbul doğumlu olmadığı, buraya başka illerden göç etmiş kişilerden oluştuğunu göstermektedir. Ancak son zamanlarda, geçim zorluğu, altyapı ve çevresel sorunlar gibi bir takım faktörlerin İstanbul'a olan iç göçü azalttığı düşünülmektedir. Belirli bir bölgenin aldığı göç ile verdiği göç arasındaki farkı gösteren net göç verilerine bakıldığında, 2016 yılında 369.582 kişinin İstanbul'a göç ettiği, 440.889 kişinin ise İstanbul'dan diğer illere göç ettiği görülmektedir. Aldığı göç ile verdiği göç farkı dikkate alındığında, özellikle son yıllarda, İstanbul göç alan bir şehir olmaktan uzaklaşıp gittikçe göç veren bir şehir haline dönüșmüștür. Ancak Türkiye geneline baktığımızda, İstanbul yine de en fazla göç edilen il olma özelliğini korumaktadır.

İç göç özellikle işgücü piyasasının işleyişinde, kırsal ve kentsel alanlardaki farklılığın azaltılmasında dengeleyici bir etkiye sahip olması açısından oldukça önemlidir. Bunun yanında emeğin düşük verimli olduğu bölgelerden yüksek verimli alanlara transferi açısından göçün olumlu etkilerinin olduğunu vurgulayan (Ghatak, 1991) çalışması gibi çalışmalar da bulunmaktadır. Buna karşın iç göçün daima olumlu etkisinin olmadığı, negatif etkilerinin de bulunduğunu vurgulayan çalışmalar da vardır. Bu çalışmalardan Tunalı (2000) 1963-1973 döneminde göçün getirisinin çoğu göçmen için negatif olduğunu göstermektedir. Bu olumsuzluklardan hem göçmenler hem de toplum büyük ölçüde etkilenmektedir. Dolayısıyla Lucas'ın belirttiği gibi, iç göç işgücü kullanımının etkinsizliği, genel yoksulluk, hızlı kentsel büyümeden kaynaklanan altyapı sorunları gibi konuların çok ötesinde sorunlar barındırabilmektedir (Lucas, 1997, s.727). Dolayısıyla, hem toplum hem de göçmenler göçün olumsuz getirilerin tüm sonuçlarıyla karşı karşıya kalmaktadır (Filiztekin \& Gökhan, 2008, s.2). Göçmenler ve toplum açısından hem olumlu hem de olumsuz etkilere sahip olduğu çeşitli çalışmalar ile 
ortaya konulan göçün belirleyicilerinin doğru bir şeklide ortaya konulup analiz edilmesi oldukça önem taşımaktadır. Türkiye'de iç göç ile ilgili çalışmalara baktığımızda, göçü etkileyen faktörler olarak oldukça çeșitli değișkenler kullanıldığını görmekteyiz. Ancak bu çalışmalara genel olarak iç göçe neden olan ekonomik, sosyal, kültürel ve güvenlik gibi geleneksel faktörlerin Türkiye için de geçerli olduğunu ortaya koymaktadır.

Türkiye'deki iç göçü araștıran literatürdeki mevcut çalıșmalarda genellikle çekim modelinin tercih edildiği görülmektedir. Bu çalışmalardan Munro (1974), Gündüz ve Yetim (1997), Gedik (1997), Gezici ve Keskin (2005), Filiztekin ve Gökhan (2008) ve Akarca ve Tansel (2018) öne çıkan çalışmalardır. Mevcut çalışmalarda çekim modelinin tahmini genellikle en küçük kareler (OLS) yöntemi kullanılarak gerçekleştirilmiştir. Ancak, OLS yöntemi gibi, geleneksel yöntemler ile çekim modelinin ekonometrik tahmini çeşitli sorunlar barındırmaktadır. Silva ve Tenreyro (2006) çalışmasında logaritması alınarak doğrusal hale getirilen çekim modelinin hata teriminin değișen varyanslı olması durumunda, logaritmik hata teriminin beklenen değerinin diğer açıklayıcı değișkenler ile bağımsız olmadığını belirtmektedir. Böyle bir durumda, çekim modelinin tutarsız tahminler verdiğini göstermişlerdir. Çekim modelindeki diğer bir sorun, yerçekimsel gücün asla sıfır değer alamayacağı, fakat çekim modelinde iki bölge arasındaki göçün sıfır olabileceği gerçeğinin uygulamada nasıl ele alınacağıdır. Bu durum, logaritması alınarak doğrusal hale getirilip tahmini yapılan çekim modelinin, bağımlı değişkendeki sıfır değerini alan gözlenmelerin logaritmasının alınamamasına, dolayısıyla modelin tahmininde soruna neden olmaktadır. Bu soruna çözüm olması amacıyla, genellikle iki alternatif yaklaşım önerilmektedir. Literatürdeki çoğu deneysel çalışmada sıfır değerine sahip değerler veri setinden çıkarılarak, çekim modeli OLS ile tahmin edilmektedir. Ancak, bu gözlemleri veri setinden çıkarmak başka sorunlara neden olmaktadır. Bu sorunlardan ilki Eichengreen ve Irwin (1996) çalışmasında belirtildiği gibi silinen gözlemlerdeki bilginin kaybolması. İkinci sorun ise, Burger, Van Oord ve Linders (2009) çalışmasında ortaya konulan, sıfır değerine sahip gözlemlerin dağılımının rastgele olmayan bir dağılımdan gelmesi durumunda, bu gözlemlerin silinmesi örneklem seçim problemine (sample selection problem) neden olacağıdır. Diğer taraftan, bazı çalışmalarda bağımlı değişkendeki sıfır değerlerine sahip gözlemlerin yerine çok küçük pozitif bir sayı dâhil edilmektedir. Ancak, Flowerdew ve Aitkin (1982) çalışmasında sıfır değerleri yerine konulması için seçilen çok küçük sayının aldığı değere göre, parametre tahminlerinin oldukça fazla değiștiğini göstermiștir. Çekim modelinin tahmininde bahsi geçen sorunlara çözüm olması amacıyla, Silva ve Tenreyro (2006) çalışması Poisson Pseudo Maksimum Olabilirlik (PPML) tahmincisini önermiștir. Bu tahminci belirtilen sapmayı düzeltip tutarlı tahminler vermesinin yanında, iki bölge arasında hiç göç olmaması durumunda, bağımlı değişkenin aldığı sıfır değerler ile ilgili soruna da çözüm getirmektedir (Babkova, 2012, s.6; Silva \& Tenreyro, 2011, s.222). Türkiye'de çekim modeli yardımıyla iç göçü araştıran literatürdeki mevcut çalışmalarda, çekim modelinin tahmininde çoğunlukla bu sorunları dikkate alamayan OLS gibi yöntemler tercih edilmiștir. Bu durum, yukarıda bahsedilen nedenlerden dolayı, mevcut çalıșmalarda elde edilen sonuçların tutarsız veya sapmalı olabileceği ihtimalini doğurmaktadır ve sonuçların doğruluğuna ilişkin kuşkulara neden olmaktadır. Dolayısıyla, bu çalışmanın amacı çekim modelinin tahmininde alternatif tahmin teknikleri arasında uygun tahmin tekniğini belirleyerek, İstanbul'a yönelik iç göçü çekim modeliyle araştırmaktır. İstanbul'a yönelik iç göçün çekim modeliyle araştırıldığı bu çalışma, literatürdeki diğer çalışmaların aksine, çekim modelinin tahminde tutarlı tahminler verebilen Poisson sabit ve rassal etkiler tahmincisi, Poisson Pseudo Maksimum Olabilirlik (PPML) tahmincisi gibi havuzlanmış OLS ve geleneksel panel veri tahmincilerine alternatif tahmincilerin karşılaștırılarak, uygun yöntemin belirlendiği ilk çalıșma olma özelliğindedir. 


\section{Literatür}

İç göç ile ilgili hem ulusal hem de uluslararası oldukça geniș bir literatür bulunmaktadır. Özellikle, Etzo (2011), Anderson (2011) ve Poot, Alimi, Cameron ve Mare (2016) çalışmaları göç ve çekim modeline ilişkin kapsamlı literatür özeti sunmaktadır. Türkiye'de geçmiş dönemde yapılan iç göç çalışmalarına baktığımızda, Gedik (1997) Türkiye'deki iç göç verilerini inceleyerek, 1965-1985 arasında Türkiye'deki iç göçün gelişmekte olan ülkeler için göç literatüründeki bulgular ile çelişkili olduğunu test etmiştir. Bu çalışmada bilgi, risk alma yeteneği ve sosyal bağlantılar gibi faktörler, gelişmekte olan ülkelerin aksine, Türkiye'de kırsaldan kente göçü etkilenmenin yanında, kentten kente ve kentten kırsala dönüşte itici bir faktör olduğunu göstermiştir. Dahası, bu çalıșma iç göç konusunda mesafenin yerine akraba veya sosyal bağların daha etkili olduğunu ortaya koymuştur. Gezici ve Keskin (2005) çalışmasında ise OLS regresyonuyla, 1990 nüfus sayımı verilerini kullanarak bölgesel eşitsizlikler ile iç göç arasındaki ilişkiyi araștırmıştır. Çalışmada iç göç üzerinde etkisi bulunan değişkenleri Gayrı Safi Milli Hasıla (GSMH), işgücü ve yıllık nüfus artışı olarak bulunmuştur. Ayrıca, Türkiye'nin batı bölgelerinde bulunmanın, kıyı şehri olmanın ve endüstri ve turizm açısından gelişmiş olmanın net göç üzerinde pozitif etkisi olduğu bulunmuştur. Evcil, Dökmeci ve Kıroğlu (2006) çalışmasında ise 1990 ve 2000 ylllarına ait veriler kullanılarak iç göçü adımsal regresyon analizi yöntemiyle incelemiştir. GSMH değişkenin iç göç üzerinde en etkili değişken olduğunu bulmuştur. Filiztekin ve Gökhan (2008) çalışmasında ise 1990 ve 2000 nüfus sayımlarını kullanarak Türkiye'deki iç göçün belirleyicilerini çekim modeli yardımıyla araştırmıştır. Çalıșmada gelir farklılığı, işsizlik oranı ve sosyal bağların varlığı gibi sosyal faktörlerin Türkiye'deki iç göç üzerinde anlamlı bir etkiye sahip olduğu bulunmuștur. Çalışmada logaritması alınarak doğrusal hale gelen çekim modelinin tahminindeki teorik sorunlara değinilmemiştir. Akarca ve Tansel (2017) çalışması Türkiye'nin güney batısına yönelik iç göçü analiz etmiştir. Çalışmada, çeşitli istatistiksel yöntemler yardımıyla iç göç için geleneksel çekim faktörlerinden farklı olarak, bu bölgelerin endüstri ve kentleşme bakımından yoğun olmamasına rağmen birer çekim merkezi olmalarının literatürdeki diğer çalışmalardan farklı olduğu ortaya konulmuştur. Bu alandaki son çalışma olan, Akarca ve Tansel (2018) makalesi Antalya ve Muğla'ya yönelik iç göçün nedenlerini iki ayrı çekim modeli yardımıyla araștırmıştır. Çekim modelinin tahmininde OLS ve dirençli regresyon tahmincileri kullanılmıştır. Çalışmada, göreli işsizlik oranı, önceki göç miktarı, nüfus ve doğal felaketlerin iç göçü arttırdığı, mesafenin ise kısalttığı sonuçları bulunmuştur. Ancak bu çalışmada tahmin edilen çekim modeli için sabit varyans varsayımı sınanmamıştır. Logaritması alınarak doğrusal hale getirildikten sonra tahmin edilen çekim modelinde göçmen akışı yerine, göçmen akışının logaritması tahmin edilmektedir. Dahası, Haworth ve Vincent (1979) çalışmasında ortaya koyduğu gibi, bu değerlerin anti-logaritmasının alınması sapmalı tahminler vermektedir. Özetle, Türkiye'de iç göçü araştıran literatürdeki çalışmalar, çekim modelinin tahmin edilmesinde karşılaşılan sorunlara yönelik bir çözüm sunmamaktadır. Dolayısıyla, çekim modelinden elde edilen tahminlerin sapmalı ve tutarsız olma ihtimali bulunmaktadır. Sonuç olarak, çekim modelinin tahmininde ekonometrik ve teorik açıdan uygun tahmin tekniğinin kullanılması oldukça önemlidir. Türkiye'de iç göçün araştırıldığı literatürde çekim modelinin tahminindeki yukarıda bahsedilen sorunların dikkate alındığı herhangi bir çalışmaya rastlanmamıştır. $\mathrm{Bu}$ bakımdan bu çalışma literatüre önemli bir katı sağlayacağı düşünülmektedir. 


\section{Yöntem}

Çalıșmada, İstanbul'a yönelik iç göç çekim modeli yardımıyla araștırılmaktadır. Çekim modelinin tahmininde modelin logaritmasının alınarak tahmini daha önce belirtildiği gibi çeşitli sorunlara neden olmaktadır. Bu sorunlardan ilki, göçmen akışının kendisi yerine onun logaritmasının tahmin edilmesidir. Dolayısıyla göçmen akışının kendisini bulmak için bu tahminlerin anti-logaritmasının alınması, Haworth ve Vincent (1979) çalıșmasında belirtildiği üzere, ilgilenilen değișkenlerin sapmalı tahminler vermektedir. $\mathrm{Bu}$ sapma Jensen'in eșitsizliğ ${ }^{1}{ }^{1}$ ile ilișkilidir. Bunun yanında, bağımlı değişkenin sıfır değerini alması ve logaritmik doğrusal olan çekim modelinin tahmininde sorunlara neden olmaktadır. Ayrıca çekim modelinin hata teriminde değișen varyans sorunu olması durumunda logaritmik-doğrusal çekim modelinin OLS ile tahmini tutarsız sonuçlar vermektedir. Dolayısıyla çekim modelinin tahmin edilebilmesinde karşılaşılan teorik sorunların üstesinden gelebilmek ve uygun tahmin yöntemini belirleyebilmek için çeşitli panel veri modellerinden yararlanılmıştır, havuzlanmış, sabit ve rassal etkiler. Tüm yöntemler hem geleneksel yolla hem de Poisson tahminciler kullanılarak tahmin edilmiştir. Sabit etkiler modelinin tahmininde zamanla değişmeyen ya da çok az değișen değişkenler modelden düşmektedir. Ancak çekim modelinde mesafe gibi zamanla değişmeyen değişkenlerin göç üzerindeki etkisini bilmek oldukça önemlidir ve modelde bulunması gerekmektedir. Sabit etkiler tahminindeki bu sorunu çözmek için çekim modeli farklı bir şeklide tahmin edilmesi gerekmektedir. FE yerine göç veren iller için sabit etkiler regresyonu önerilmektedir. Bunun temel varsayımı göç veren illerin sabit etkileri, illere özgü kukla değişkenler ile vekil değişken olarak kullanılabilmesidir. $\mathrm{Bu}$ şekilde, çekim modeli panel yöntemleri kullanılmadan tahmin edilebilmektedir. Yani klasik çerçevede havuzlanmış OLS, Poisson çerçevesinde ise PPLM tahmincisi kullanılabilir (Babkova, 2012, s.28). Çalışmada uygun modelin belirlenebilmesi için bazı testlerden yararlanılmıștır. PPML tahmincisi modelde spesifikasyon hatası olmaması durumunda sapmasiz ve tutarlı tahminler vermektedir. Dolayısıyla tahmin edilen modellerde model belirlenme (spesifikasyon) hatasının olup olmadığı Ramsey'in Reset Testi (Ramsey Regression Equation Specification Error Test) yardımıyla araștırılmıştır. Boş hipotezin reddedilmesi modelde belirlenme hatası olduğunu göstermektedir². Ayrıca logaritmik dönüşümün nasıl bozucu bir etki yarattığını tespit etmek için 1'nolu denklemde verilen uyum iyiliği istatistiğinden ${ }^{3}$ yararlanılmıștır.

$$
\chi_{\text {red }}^{2}=\frac{1}{N-k-1} \sum \frac{\left(\hat{y}_{i j t}-y_{i j t}\right)^{2}}{\sigma^{2}}
$$

Burada, $\hat{y}_{i j t}$ tahmin edilen göçü, $y_{i j t}$ gerçek göçü, $\sigma^{2}$ ölçüm hatasının veryansını, N gözlem sayısını k ise modeldeki parametre sayısını belirtmektedir.

\section{1. Çekim Modeli}

Çekim modeli Newton'un yerçekimi yasasına dayanmaktadır. Bu yasa iki cisim arasındaki çekimi, cisimlerin kütleleri ile doğru, iki kütle arasındaki mesafe ile ters

\footnotetext{
${ }^{1}$ Bir rastgele değişkenin beklenen değerinin logaritması logaritmasının beklenen değerinden küçük eşittir, $\ln E[\mathrm{z}] \leq \mathrm{E}[\operatorname{lnz}]$.

${ }^{2}$ OLS durumunda F testi, Poisson regresyon durumunda ise Ki-kare testi yardımıyla bu hipotez test edilmiștir

${ }^{3}$ Formülün kaynağı: $\underline{w w w . w i k i p e d i a . c o m ~}$
} 
orantılı olarak ilişkilendirmektedir. Çekim modelinin göçe uyarlanmış hali, göç veren bölgeden göç edilen bölgeye özgü çarpımsal olarak birleşmiş itici ve çekici faktörler ile mesafenin bir fonksiyonu olarak tanımlanmıştır. Bu şeklide tanımlanan göçe özgü çekim modeli aşağıdaki gibi yazılmaktadır.

$$
M_{i j}=A_{i} \cdot B_{j} \cdot f\left(\mathrm{D}_{i j}\right)
$$

Burada $i$ kaynak bölge $j$ göç edilen bölgeyi, $M_{i j} i^{\prime}$ den $j^{\prime}$ ye göç eden göçmen sayısını, $A_{i}$ ve $B_{j}$ kaynak ve göç edilen bölgelere özgü itici ve çekici faktörleri, $D_{i j}$ ise göçmen akışını etkileyen $i$ ile $j$ arasındaki mesafeyi göstermektedir. Burada $f($.) fonksiyonu, mesafenin artmasının göçmen akıșını yavașlatacağını belirten, monoton bir ters fonksiyonu göstermektedir (Molho, 1986, s.406; Filiztekin \& Gökhan, 2008, s.14).

Göçe uyarlanmıș bașka bir çekim modeli ise Bauer ve Zimmerman (1999) ve Karemera, Oguledo ve Davis, (2000) tarafindan arz - talep denklem sistemiyle tanımlanmaktadır.

$$
M_{i j}=f\left(\mathrm{~S}_{i}, D_{j}, C_{i j}\right)
$$

Burada $S_{i}$ kaynak bölgedeki arz (itici) faktörleri, $D_{j}$ ise göç edilen bölgedeki talep (çekici) faktörleri göstermektedir. $C_{i j}$ ise $i$ bölgesinden $j$ bölgesine gitmenin maliyetini göstermektedir. Burada çekim modeli Newton'un yasasına uygun olarak iki bölge arasında itici ve çekici faktörlerin çarpımı ile doğru, $i$ bölgesinde $j$ bölgesine gitmenin maliyeti ile ters orantılı olarak yazılabilir.

Çarpımsal formda çekim modeli așağıdaki gibi yazılmaktadır.

$$
M_{i j}=\alpha_{0} \frac{\left(\mathrm{S}_{i} \times D_{j}\right)^{\alpha_{1}}}{C_{i j}^{\alpha_{2}}} u_{i}
$$

Bu modelin logaritması alınıp doğrusal hale getirilerek bilinmeyen parametreler en küçük kareler (OLS) yöntemiyle tahmin edilmektedir. Denklemdeki katsayılar ise esneklikleri vermektedir.

$$
\log M_{i j}=\alpha_{0}+\alpha_{1} \log \left(\mathrm{S}_{i} \times D_{j}\right)-\alpha_{2} \log \mathrm{C}_{i j}+\log u_{i}
$$

Burada, $M_{i j}$ kaynak bölgeden göç edilen bölgeye yapılan bürüt göçmen akışını göstermektedir. Burada net göç yerine bürüt göç kullanılmasının nedeni net göçün her iki yöndeki itici ve çekici faktörleri birbirinden ayıramamasıdır (Bauer \& Zimmerman, 1999; Filiztekin \& Gökhan, 2008, s.3-4). Modeldeki $\alpha$ 'lar ise tahmin edilecek bilinmeyen parametreleri göstermektedir. Bu modele, ayrıca, göçmen akışı üzerine etkisi olan bazı değişenler eklenerek genişletilmiş çekim modeli de oluşturulabilmektedir.

\subsection{PPML Tahmincisi}

Çekim modelinin parametrelerinin OLS ile tutarlı bir şekilde tahmin edilebilmesi için hata teriminin, açıklayıcı değişkenler ile bağımsız olması gerekmektedir. Ancak, Jensen'in eşitsizliğinden $E(\log Y) \neq \log E(Y)$, Silva ve Tenreyro (2006) çalıșmasında hata teriminin değişen varyanslı olması durumunda, logaritmik hata teriminin diğer açıklayıcı değişkenler ile bağımsız olmadığını belirtmektedir. $\mathrm{Bu}$ 
durumda, çekim modelinin tutarsız tahminler verdiğini göstermișlerdir. Çekim modelindeki diğer bir sorun ise, daha önce belirtildiği gibi, çekim modelinde iki bölge arasında göçün sıfır olabileceği gerçeğinin model tarafından nasıl ele alınacağıdır. Bağımlı değişkendeki sıfır değerler logaritmasının alınamadığından dolayı çekim modeli tahmininde genellikle soruna neden olmaktadır. Bu soruna özüm olması için bağımlı değişkendeki sıfır değerleri yerine çok küçük bir değerin verilmesi ya da sıfır değerini alan gözlemlerin veriden çıkarılması bu sorunu çözememektedir.

Logaritmik hata teriminin diğer açıklayıcı değișkenler ile bağımsız olmadığı durumda, dönüștürülmüş hata teriminin etkin tahmincisini elde edebilmek için Silva ve Tenreyro (2006) çalışmasında, McCullagh ve Nelder (1989) tarafından önerilen PML tahmincisinin așağıda verilen birinci sıra koșulunun numerik olarak Poisson Pseudo Maksimum Olabilirlik (PPML) tahmincisinden farklı olmadığını göstermiștir. Yani, 6'nolu denklemde verilen tahminci nümerik olarak PPML (Posisson Pseudo-Maximum Likelihood) tahmincisine eșittir. Dolayısıyla, bu bulgu PPML tahmincisinin çekim modelinin tahmininde kullanılabileceğini ortaya koymaktadır.

$$
\sum_{i=1}^{n}\left[y_{i}-\exp \left(\mathrm{x}_{i} \tilde{\beta}\right)\right] x_{i}=0
$$

Silva ve Tenreyro (2006), verinin Poisson tipi bir dağılıma sahip olması gerekmeksizin, sadece koşullu ortalamanın doğru bir şekilde belirlenmiș olması şartıyla, PPML tahmincisini sapmasız ve tutarlı tahminler vereceğini göstermiștir. Ayrıca, akış (göçmen) ile ilgili verinin Poisson dağılımına uymaması durumunda PPML tahmincisinin tutarlı tahminler vereceği Gourieroux, Monfort ve Trognon (1984) çalışmasında da ortya konulmuştur. Çekim modelindeki diğer bir sorun olan modeldeki bağımlı değişkenin sıfır değerleri alabilmesinin PPML tahmincisinin doğru sonuçlar vermesini etkilemediği Silva ve Tenreyro (2011) çalışmasında yapılan simülasyon çalıșmasıyla gösterilmiştir.

Panel veri durumunda çekim modelinin tahmininde illere özgü gözlenemeyen heterojen etkili çekim modeli uygulanmaktadır. Sabit etkiler tercih edilmesi durumunda modelde olması gereken zaman değişmezi değişkenlerinin tahmini için kukla değişken sabit etkiler regresyonu tercih edilmektedir (Babkova, 2012, s.22). Bu regresyonda hata teriminde değișen varyans sorunu olması durumunda bu tahminci tutarl tahminler verememektedir (Silva \& Tenreyro, 2006, s.653). Çekim modelinin logaritmik dönüșümün tahmininin panel veri kullanılması durumunda, sabit ve rassal etkiler tekniğinin geçerli sonuçlar verebilmesi için log-doğrusal çekim modelinin hata teriminin logaritmasının koşullu beklenen değerinin sıfıra eşit olması gerekmektedir. Ancak, Westerlund ve Wilhelmsson (2011) çalıșmasıyla bunun her zaman doğru olmadığını göstermiştir. Bu durumda, geleneksel sabit etkiler tahmincisinin sapmalı ve etkinsiz olduğu belirtilmektedir. Dolayısıyla Westerlund ve Wilhelmsson (2011) çalışmasında logaritmik-doğrusal çekim modelinin tutarlı ve etkin tahmin edebilmek için sabit etkiler Poisson Pseudo Maksimum Olabilirlik tahmincisinin bootstrap standart hatalar ile kullanılmasını önermektedir. Buradan elde edilen parametre tahminleri doğrudan esneklik olarak yorumlanabilmektedir.

\section{Model ve Veriler}

İstanbul'a yönelik göç akışı çekim modeliyle araştırılacaktır. Çekim modeli iki bölge arasındaki göç akışını açıklamada oldukça yaygın bir yaklaşımdır. Poot vd. (2016) çalışmasında belirtildiği gibi, çekim modelin en önemli özelliği göç teorileri ile olan tutarlılığıdır. Ayrıca, deneysel çalışmalarda kolay tahmin edilmesi ve modelin iyi uyum sergilemesi çekim modelini oldukça popüler hale getirmiştir. Literatürdeki çoğu 
çalışmada belirtildiği gibi, temel çekim modeli, iki bölge arasındaki göçmen akışı, bu iki bölgenin nüfusu, iki bölge arasındaki mesafe, iki bölge arasında gerçekleşmiş önceki yıllardaki göçmen sayıları ve iki bölge arasındaki işsizlik ya da ücret oranlarındaki farklılığın bir fonksiyonu olarak oluşturulmaktadır. Temel modeldeki değişkenlere ilișkin beklentiler șu șekilde sıralanmaktadır: Göç veren ve alan bölgelerin nüfusunun fazla olması, bu bölgelerde göç oranını arttırması beklenmektedir. Göçün nedenlerinden belki de en önemlisi ekonomik nedenlerdir. Göçün, işsizliğin yüksek olduğu bölgeden, düşük olduğu bölgeye ya da ücretlerin düşük olduğu bölgeden yüksek olduğu bölgeye doğru olması beklenmektedir. Göç edilen bölgeler arasındaki mesafenin artmasının maliyetler ile ilişkilendirilerek göç eden insan sayısını azaltacağı beklenmektedir. Bunun yanında, Akarca ve Tansel (2018)'in belirttiği göç edilen bölgede arkadaş, akraba gibi bir bağın olması geçmiș dönemlerdeki göç ile ilișkilendirilerek, yeni bir yere yerleșmede kişilerin sevdiklerinden uzak kalmamasını ve iş bulma olasılığını güçlendirmektedir. Ayrıca, cari işsizlik oranları ve ücretler gelecekteki işsizlik oranları ve ücretler için vekil değişken olarak kullanılmaktadır.

Bunun yanında, literatürde temel çekim modeline iç göçü etkileyecek bazı değişkenler eklenerek genişletilmiş çekim modeli oluşturulmaktadır. Filiztekin ve Gökhan (2008) çalışmasında göç veren ildeki genç nüfus oranı değişkeni ile eğitim süresini kullanmıştır. Bu değișkenlerin göç üzerine pozitif etkiye sahip olacağı belirtilmiştir. Ancak, Akarca ve Tansel (2018) çalışmasında genç nüfus oranı ve eğitim değişkenlerinin birbiriyle ve temel modelde bulunan işsizlik oranı değişkeniyle ilișkili olacağı gerekçesiyle bu değişkenlerin kullanılmasının uygun olmayacağını belirtmektedir. Çünkü işsizlik oranının yüksek olması genellikle ortanca yaşın ve eğitim seviyesinin düşük olmasıyla ilişkilendirilmektedir. Aynı çalışmada kentleşme ve iklim değişkenlerinin göç üzerine anlamlı bir katkı sağlamadığı da belirtilmektedir. Dolayısıyla bu çalıșmada İstanbul'a yönelik iç göçü açıklamak için kullanılan model, Akarca ve Tansel (2018) çalışmasında kullanılan çekim modeline uymaktadır. Bu çalışmada, çekim modeli çok bölgeli ya da iki bölgeli modellerden farklı olarak, Türkiye'deki diğer tüm illerden İstanbul'a yönelik göçmen akışını tek yönlü olarak dikkate almaktadır.

$$
\ln M_{i j t}=\alpha_{0 j}+\alpha_{1} \ln P_{i t}+\alpha_{2} \ln D_{i j}+\alpha_{3} \ln \left(\mathrm{U}_{i t} / \mathrm{U}_{j t}\right)+\alpha_{4} \ln H_{i j t}+\varepsilon_{i j t}
$$

Burada, $M_{i j t}$ 2008-2013 döneminde $i$ ilinden $j$ iline göç eden toplam insan sayısını göstermektedir, $P_{i t}$ göç veren ilin nufusunu, $D_{i j}$ göç veren il ile İstanbul arasındaki mesafeyi km cinsinden göstermektedir. $U_{i t}$ göç veren ildeki ișsizlik oranını, $H_{i j t}$ ise $i$ ilinde doğup İstanbul'da ikamet eden kişilerin sayısını göstermektedir. İstanbul'un nufusu tüm gözlemler için sabit olduğunda modelde kullanılmamıştır. Adrese dayalı nüfus kayıt sistemine geçildikten sonra 2008 yılından itibaren her yıl için yıllık göç verileri TÜíK tarafından yayınlanmaktadır. Dolayısıyla, göçün etkilediği değişkenlere ait göç alan ve veren illerdeki değişim yıllık olarak ölçülebilmektedir. Ancak işsizlik oranlarına ait veriler il düzeyinde 2008-2013 dönemi için bulunduğu için çalışmanın dönemi 2008-2013 yılları arasına sınırlandırılmıștır. Dolayısıyla çalıșmada 2008-2013 dönemini kapsayan altı yıl ve 80 ile ait (ve diğer il olan İstanbul) panel veri kullanılmaktadır. Çalışmada, mesafe verisi Karayolları Genel Müdürlüğü'nden, diğer veriler ise Türkiye İstatistik Kurumundan (TÜİK) temin edilmiștir. 


\section{Bulgular}

Çekim modeli teorisine göre geçerli model spesifikasyonunu belirlemek için havuzlanmış, sabit etkiler ve rassal etkiler modelleri olmak üzere üç ayrı model olușturulmuștur. Bu modeller hem geleneksel yöntemle hem de Poisson tahminciler kullanılan tahmin edilmiştir. Uygun modelin belirlenmesi için bir dizi testlerden yararlanılmıștır. PPML tahmincisi modelde belirlenme (spesifikasyon) hatası olmaması durumunda sapmasız ve tutarlı tahminler vermektedir. Dolayısıyla tahmin edilen modellerde Reset Testi (Ramsey Regression Equation Specification Error Test) yardımıyla spesifikasyon hatasının olup olmadığı araștırılmıştır. Ayrıca, modelin veriye uygunluğunu sınamak için uyum iyiliği testi gerçekleştirilmiştir. Tablo 1'de verilen Reset testi sonuçları her iki modelde spesifikasyon hatası olmadığını göstermektedir. Diğer taraftan Silva ve Tenreyro (2006) çalışmasında belirttiği üzere hata teriminin değișen varyanslı olması durumunda logaritmik-doğrusal çekim modelinin OLS ile tahmini tutarsız sonuçlar vermektedir. Dolayısıyla çalışmada çekim modelinin hata teriminin değişen varyanslı olup olmadığı Breusch-Pagan (1979) testiyle araştırılmıștır. Elde edilen bulgular çekim modelinin hata teriminde değişen varyans sorunu olduğunu göstermektedir. Dolayısıyla değișen varyans altında tutarlı tahminler veren PPML tahmincisi yardımıyla çekim modeli tahmin edilmiştir. PPML tahmincisi doğrudan değișen varyans sorununu dikkate alabilmektedir. Ayrıca her iki modele ilișkin uyum iyiliği testleri sonucuna bakıldığında PPML tahmininin veriye daha iyi uyduğu görülmektedir. Bu sonuçlar PPML yönteminin OLS yöntemine göre daha uygun bir yöntem olduğunu göstermektedir. Tablo1'de OLS ve PPML yöntemleriyle çekim modelinin tahmin sonuçları verilmektedir.

\begin{tabular}{|c|c|c|}
\hline Değişkenler & $\begin{array}{c}\text { (1) } \\
\text { Havuzlanmış-OLS }\end{array}$ & $\begin{array}{c}(2) \\
\text { PPML }\end{array}$ \\
\hline LnP & $\begin{array}{l}0,529^{* * *} \\
(0,0215)\end{array}$ & $\begin{array}{l}0,550^{* * *} \\
(0,0475)\end{array}$ \\
\hline LnD & $\begin{array}{l}-0,273^{* * *} \\
(0,0332)\end{array}$ & $\begin{array}{l}-0,328^{* * *} \\
(0,0863)\end{array}$ \\
\hline $\operatorname{Ln} U$ & $\begin{array}{l}0,200^{* * *} \\
(0,0526)\end{array}$ & $\begin{array}{l}0,0713 \\
(0,127)\end{array}$ \\
\hline LnH & $\begin{array}{l}0,549 * * * \\
(0,0250)\end{array}$ & $\begin{array}{l}0,533^{* * *} \\
(0,0658)\end{array}$ \\
\hline Sabit & $\begin{array}{l}1,131^{* * *} \\
(0,357)\end{array}$ & $\begin{array}{l}1,565^{*} \\
(0,923)\end{array}$ \\
\hline $\begin{array}{l}\text { RESET Testi } \\
\text { Olasillk }\end{array}$ & $\mathrm{F}(1,474)=2,13$ & $\operatorname{chi} 2(1)=0,61$ \\
\hline $\begin{array}{l}\text { BP Testi } \\
\text { Olasılık }\end{array}$ & $\begin{array}{c}\operatorname{chi} 2(1)=12,69 \\
(0.0004)\end{array}$ & \\
\hline Uyum İyiliği Testi & 1,1479 & 1,0466 \\
\hline Gözlem Sayısı & 480 & 480 \\
\hline
\end{tabular}

Tablo 1. OLS ve PPML Tahmin Sonuçları, 2008-2013.

İstanbul'a yönelik göçmen akışına ait OLS tahmin sonuçlarına baktığımızda. Tüm parametrelerin anlamlı olduğu görülmektedir. Beklentilere uygun olarak, İstanbul ile diğer iller arasındaki mesafeyi gösteren değişken dışındaki diğer tüm katsayılar pozitif bulunmuştur. Diğer taraftan PPML tahmin sonuçlarına baktığımızda İstanbul ile göç 
veren ilin arasındaki göreli işsizlik oranı değişkeninin OLS sonuçlarının aksine anlamlı çıkmadığı görülmektedir. Çekim modelinin PPML tahmincisiyle elde edilen parametre tahminleri esneklik olarak yorumlanabilmektedir. Elde edilen bulgular göç veren ilin nüfusunda meydana gelecek yüzde 1 oranındaki artışın, İstanbul'a göçü yüzde 0,5 oranında arttıracağını göstermektedir. Mesafe değișkenine ait tahmin edilen katsayısı ise beklentilere uygun olarak negatif bulunmuştur. Bu sonuç İstanbul ile göç veren il arasındaki mesafenin artmasının göç eden kişi sayısını yaklaşık yüzde 33 azalacağı anlamına gelmektedir. Daha önce İstanbul'a göç etmiş kişilerin sayısının yüksek olması beklendiği gibi İstanbul'a yönelik göçü arttıracağı bulgusu elde edilmiştir. Buna göre başka illerden İstanbul'a göç etmiş kişi sayısındaki yüzde 1'lik artış İstanbul'a göçü yüzde 0,5 arttırmaktadır. Bu sonuç, İstanbul'a yönelik göçün ilerleyen zamanlarda daha fazla göçe neden olacağı anlamına gelmektedir.

Göç veren illere özgü sabit etkilerin modele dâhil edildiği sabit etkiler modellerine ait sonuçlar Tablo 2'de verilmiștir. Öncelikle modellerde belirlenme hatası olup olmadığını araştırmak için Reset testi yapılmıștır. Test sonuçları Poisson sabit etkiler modelinde spesifikasyon hatası olmadığını, sabit etkiler modelinde ise spesifikasyon hatası olduğunu göstermektedir. Diğer taraftan, uyum iyiliği testleri geleneksel sabit etkiler modelinin Poisson sabit etkiler modeline göre veriye daha iyi uyum gösterdiğini belirtmektedir.

\begin{tabular}{|c|c|c|}
\hline Değișkenler & $\begin{array}{l}\text { (1) } \\
\text { FE }\end{array}$ & $\begin{array}{c}(2) \\
\text { FE-Poisson } \\
\end{array}$ \\
\hline $\ln p$ & $\begin{array}{c}1,526^{* * *} \\
(0,247)\end{array}$ & $\begin{array}{c}1,665^{* * *} \\
(0,333)\end{array}$ \\
\hline Ind & $\begin{array}{c}-1,313^{* * *} \\
(0,289)\end{array}$ & $\begin{array}{c}0,291 \\
(0,292)\end{array}$ \\
\hline $\ln u$ & $\begin{array}{l}-0,026 \\
(0,024)\end{array}$ & $\begin{array}{l}-0,043 \\
(0,033)\end{array}$ \\
\hline $\operatorname{lnh}$ & $\begin{array}{l}-0,094 \\
(0,102)\end{array}$ & $\begin{array}{c}-0,043 \\
(0,175)\end{array}$ \\
\hline Sabit & $\begin{array}{c}7,784^{* * *} \\
(1,063)\end{array}$ & $\begin{array}{c}-1,023 \\
(1,868)\end{array}$ \\
\hline RESET Testi & $F(1,78)=5,34$ & $\operatorname{chi} 2(1)=2,39$ \\
\hline Olasılık & $(0,021)$ & $(0,122)$ \\
\hline Uyum İyiliği Testi & 1,014 & 1,594 \\
\hline
\end{tabular}

Not: ${ }^{* * *} \mathrm{p}<0,01,{ }^{* *} \mathrm{p}<0,05,{ }^{*} \mathrm{p}<0,1$. Standart Hatalar parantez içerisinde verilmiştir. Standart hatalar Bootstrap standart hatalarıdır.

Tablo 2. FE ve FE-Poisson Tahmin Sonuçları, 2008-2013.

Katsayı tahminlerine ilişkin elde edilen sonuçlara baktığımızda, sabit etkiler modelinde göç veren ilin nüfusu ile o ilin İstanbul'a uzaklığının anlamlı bulunduğu görülmektedir. FE-Poisson modelinde ise sadece göç veren ilin İstanbul'a yönelik göç üzerinde anlamlı bir etkiye sahip olduğu görülmektedir. Ancak, Poisson sabit etkiler modelinin tahmin edilen katsayları, çekim modeline ilişkin teorik beklentileri karşılamaktan oldukça uzaktır. Özellikle uzaklık değişkenin katsayı teorik olarak negatif beklenirken pozitif ve anlamsız bulunmuştur. Ayrıca bir ilden İstanbul'a yapılan önceki göçler ile o ildeki göreli işsizliğin İstanbul'a yönelik iç göçü azaltacağı yönündeki sonuç beklentileri karşılamamaktadır.

Çalışmada son olarak rassal etkiler modelleri kullanılarak standart ve Poisson tahmincilerinin sonuçları karşılaştırılmıștır. İllere özgü etkilerin rassal olduğu ve diğer 
açıklayıcı değişkenlerle korelasyon olmadığı varsayımı altında, rassal etkiler modeli tutarl ve etkin tahminler vermektedir. Tablo 3'de verilen Hausman testi sonucu her iki tahminciye ait rassal etkiler modeli sonuçlarının tutarsız olduğunu göstermektedir.

\begin{tabular}{|c|c|c|}
\hline Değişkenler & $\begin{array}{l}1) \\
\text { RE } \\
\end{array}$ & $\begin{array}{c}2) \\
\text { RE Poisson } \\
\end{array}$ \\
\hline $\ln p$ & $\begin{array}{c}0,576^{* * *} \\
(0,049)\end{array}$ & $\begin{array}{c}0,598^{* * *} \\
(0,019)\end{array}$ \\
\hline lnd & $\begin{array}{c}-0,216^{* * *} \\
(0,067)\end{array}$ & $\begin{array}{c}-0,317 \\
(0,024)\end{array}$ \\
\hline $\operatorname{lnu}$ & $\begin{array}{l}-0,002 \\
(0,024)\end{array}$ & $\begin{array}{c}0,023 \\
(0,045)\end{array}$ \\
\hline $\operatorname{lnh}$ & $\begin{array}{c}0,440^{* * *} \\
(0,041)\end{array}$ & $\begin{array}{c}0,063^{* * *} \\
(0,017)\end{array}$ \\
\hline Sabit & $\begin{array}{l}1,647^{* *} \\
(0,657)\end{array}$ & $\begin{array}{c}1,292^{* * *} \\
(0,253)\end{array}$ \\
\hline Hausman Testi & $\begin{array}{l}30,380 \\
(0,000)\end{array}$ & $\begin{array}{c}102,510 \\
(0,000)\end{array}$ \\
\hline Uyum İyiliği Testi & 1,046 & 1,311 \\
\hline Gözlem Sayısı & 480 & 480 \\
\hline
\end{tabular}
Standart hatalar Bootstrap standart hatalarıdır.

Tablo 3. RE ve RE Poisson Tahmin Sonuçları, 2008-2013.

Tablo 3 rassal etkiler modeli için her iki tekniğe ilişkin tahmin sonuçları özetlemektedir. Standart rassal etki modelinin tahmin edilen katsayılarına baktığımızda, göreli işsizlik değişkeni dışında diğer değişkenlerin anlamlı olduğu görülmektedir. Diğer taraftan Poisson rassal etki modelinde göreli işsizlik ve mesafe değişkeni dışında diğer değişkenler anlamlı bulunmuştur. Tahmin edilen katsayı büyüklükleri PPML modelindeki katsayı büyüklüklerine sabit etkiler modeline göre daha yakın çıkmıştır. Ayrıca uyum iyiliği testi sonucu geleneksel rassal etkiler modelinin veriye Poisson rassal etki modelinden daha fazla uyduğuna işaret etmektedir.

İstanbul'a yönelik iç göçü araştırmak için oluşturulan çekim modeli havuzlanmış, sabit ve rassal etkiler modelleri alternatif tahmin teknikleri kullanılarak tahmin edilmiştir. Standart yatay kesit ve panel veri tahmin tekniklerinin yanında Poisson tahminci yardımıyla çekim modeli tahmin edilmiştir. Havuzlanmış ve sabit etkiler çekim modelinin doğru spesifikasyonunu belirleyebilmek için yapılan Reset testi sonuçları, PPML yöntemi ile Poisson sabit etkiler sonuçları dışında, diğer tüm modellerde belirlenme hatası olduğunu göstermektedir. Hesaplanan uyum iyiliği istatistikleri ise PPML modelinin Poisson sabit etkiler modeline göre veriye daha iyi uyum gösterdiğine işaret etmektedir.

\section{Sonuç}

İstanbul, Türkiye'de iç göç alan en önemli çekim merkezi konumundadır. Ancak son yıllara ait göstergeler, İstanbul'a yönelik göçün azaldığını, İstanbul'un artık göç alan değil de göç veren bir il haline geldiğini göstermektedir. Bu çalışmada İstanbul'a yönelik iç göç, panel veri kullanılarak, çekim modeli yardımıyla araștırılmaktadır. Literatürdeki diğer çalışmalardan farklı olarak, bu çalışmada çekim modelinin tahmininde logaritmik dönüşümün olası olumsuz etkileri havuzlanmış, sabit ve rassal etkiler olmak üzere üç 
tür panel çekim modeli yardımıyla araştırılarak, uygun çekim modelinin belirlenmesi amaçlanmaktadır. Havuzlanmış modelin tahmininde geleneksel OLS tahmincisinin yanında PPML tahmincisi kullanılırken, sabit ve rassal etkiler için hem geleneksel hem de Poisson sabit ve rassal etkiler tahmincileri kullanılmıștır. Yapılan testler sonucunda, çekim modelinin OLS tahminlerinin sapmalı olduğu görülmektedir. Hausman testi sonuçları ise, hem standart hem de Poisson rassal etkiler modellerinin tutarsız olduğunu göstermiştir. Sabit etkiler modellerine ilişkin sonuçlar da ise geleneksel sabit etkiler modelinde belirlenme hatası olduğu, Poisson sabit etkiler modelinin ise veriye iyi uyum göstermeyip, tahmin edilen katsayıların çekim modelinin teorik beklentileriyle uyuşmadığı görülmektedir. Dolayısıyla bu çalışmada, İstanbul'a yönelik iç göçü araştırmak için kurulan çekim modelinin tahmininde PPML tahmincisinin en uygun tahminci olduğuna karar verilmiştir. PPML tahmincisiyle elde edilen bulgular, İstanbul'a yönelik iç göçün belirleyicilerinin, literatürdeki diğer çalışmalar tarafından ortaya konulmuş ekonomik ve sosyal faktörler olduğunu göstermektedir, yani nüfusun artması, geçmişte yaşanan göçün yüksek olması göçmen sayısını arttırmaktadır, mesafenin artması ise iç göçü azaltmaktadır. Diğer taraftan, göreli işsizliğin, beklendiği gibi, İstanbul'a yönelik iç göçü pozitif etkilediği, ancak bu etkinin, literatürdeki çoğu çalışmanın aksine, anlamlı bir etki olmadığı bulunmuştur.

Önceki çalışmalar, sosyoekonomik ve kültürel açıdan oldukça farklı özelliklere sahip bölgeler barındıran Türkiye'de iç göçün altında yatan dinamiklerin bilindik ekonomik ve sosyal nedenlerden kaynaklandığını belirtmektedir. Ancak, elde edilen sonuçlar iller arasındaki göreli işsizliğin İstanbul'a yönelik göçü arttırdığına ancak bu artışın ilgili dönemde iç göçü etkileyen önemli nedenlerden birisi olmadığına işaret etmektedir. Bu bulgu, Yüceol (2011) çalışmasında, Türkiye'deki bölgeler için elde edilen bulgulara benzerlik göstermektedir. Elde edilen bu sonuç, 2008-2013 döneminde illerdeki işsizlik oranının artmasının insanların İstanbul'a göç eğilimini etkilemediğini ve insanların işgücünden çıkarak bu duruma uyum sağlamış olabileceğine işaret etmektedir. Göç etmemeyi tercih eden işsiz bireylerin kendi illerinde kalarak işsizlik maaşı veya ekonomik destek alabilmek için aile yanında kalmak gibi yolları tercih ettiği düşünülmektedir. Bunun yanında, TÜİK'in satın alma gücü paritesi verilerine göre, özellikle İstanbul'daki konut ve barınma fiyatlarının diğer illere göre oldukça yüksek olması, bireylerin geçinebilmesi için gerekli asgari geçim seviyesinin de diğer illere klyasla İstanbul'da daha fazla olması bu sonucu destekleyen nedenler olarak sıralanabilir. Bunun dışında, özellikle kayıt dışı istihdam ve yabancı göçmenlerin aynı işte yerlilere göre düşük ücrete razı olmaları gibi faktörler ücret miktarının azalmasına neden olduğu düşünülmektedir. Tüm bu gelişmeler, İstanbul'u iș bulmak için bir çekim merkezi olmaktan uzaklaștırmakla birlikte, farklı merkezlerin iş bulmak için daha cazip olabileceğine işaret etmektedir. Ancak, işsizliğin Türkiye'de iç göç üzerine etkilerinin alternatif çalışmalar ile desteklenmesi önerilmektedir. Son olarak, elde edilen sonuçlar İstanbul'a yönelik iç göçü açıklamada özellikle bölgelere özgü bazı analizlerin yapılması gerekliliğini ortaya koymaktadır.

\section{KAYNAKÇA}

AKARCA, A. T., \& TANSEL, A. (2017). Tourism-Driven Migration to Southwestern Turkey. Bogazici Journal: Review of Social, Economic \& Administrative Studies, Vol 31 (1), 23-42.

AKARCA, A. T., \& TANSEL, A. (2018). Analyzing Internal Migration to Antalya and Muğla through Gravity Modelling. Sosyoekonomi, Cilt 26 (37), 117-126. 
ANDERSON, J. E. (2011). The gravity model. Annual Review of Economics, Vol 3 (1), 133-160.

BAUER, T. K., \& ZIMMERMANN, K. F. (1999). Assessment of possible migration pressure and its labour market impact following EU enlargement to Central and Eastern Europe (Vol. 3). Bonn: iza.

BOBKOVÁ, B. (2012). Gravity model estimation using panel data-is logarithmic transformation advisable? (Published Master Thesis). Institu of Economic Studies, Praha, Czech Republic.

BREUSCH, T. S. \& PAGAN, A. R. (1979). A simple test for heteroscedasticity and random coefficient variation. Econometrica: Journal of the Econometric Society, Vol 47 (5), 1287-1294.

BURGER, M., Van OORT, F. \& LINDERS, G. J. (2009). On the specification of the gravity model of trade: zeros, excess zeros and zero-inflated estimation. Spatial Economic Analysis, Vol 4 (2), 167-190.

EICHENGREEN, B. \& IRWIN, D. A. (1998). The role of history in bilateral trade flows. In The regionalization of the world economy (pp. 33-62). Chicago: University of Chicago Press.

ETZO, I. (2011). The determinants of the recent interregional migration flows in Italy: a panel data analysis. Journal of Regional Science, Vol 51 (5), 948-966.

EVCIL, N., DÖKMECİ, V. \& KİROGLU, G. B. (2006). Regional migration in Turkey its directions and determinants. ERSA Conference Papers.

FILIZTEKIN, A. \& A. GÖKHAN (2008). The determinants of internal migration in Turkey. In International Conference on Policy Modelling (EcoMod2008), Berlin, Germany, 2-4 July 2008.

FLOWERDEW, R. \& AITKIN, M. (1982). A method of fitting the gravity model based on the Poisson distribution. Journal of regional science, Vol 22 (2), 191-202.

GEDİK, A. (1997). Internal migration in Turkey, 1965-1985: Test of conflicting findings in the literature. Review of Urban \& Regional Development Studies, Vol 9 (2), 170179.

GEZICİ, F. \& KESKIN, B. (2005, August). Interaction between regional inequalities and internal migration in Turkey. In ERSA Conference Papers (pp. 1-18).

GHATAK, S., LEVINE, P. \& PRICE, S. W. (1996). Migration theories and evidence: an assessment. Journal of Economic Surveys, Vol 10 (2), 159-198.

GOKHAN, A. \& FILIZTEKIN, A. (2008). The determinants of internal migration in Turkey. In International Conference on Policy Modelling. EcoMod (Vol. 2008).

GOURIEROUX, C., MONFORT, A. \& TROGNON, A. (1984). Pseudo maximum likelihood methods: Theory. Econometrica: Journal of the Econometric Society, Vol 52 (3), 681-700.

GÜNDÜZ, M. \& YETİM, N. (1997). Terör ve göç. Toplum ve Göç-II. Ulusal Sosyoloji Kongresi (November 20-22, 1996, Mersin) Bildiriler Kitabı, 109-18.

KAREMERA, D., OGULEDO, V. I. \& DAVIS, B. (2000). A gravity model analysis of international migration to North America. Applied Economics, Vol 32 (13), 1745-1755.

LUCAS, R. E. (1997). Internal migration in developing countries. Handbook of population and family economics, Vol 1 (B), 721-798.

MCCULLAGH, P. \& NELDER, J. A. (1989). Generalised linear models 2nd edn. Monographs on statistics and applied probabilitity. London: Chapman and Hall. MOLHO, I. (1986). Theories of migration: a review. Scottish Journal of Political Economy, Vol 33 (4), 396-419.

MUNRO, J. M. (1974). Migration in Turkey. Economic Development and Cultural Change, Vol 22 (4), 634-653. 
POOT, J., ALIMI, O., CAMERON, M. P. \& MARÉ, D. C. (2016). The gravity model of migration: the successful comeback of an ageing superstar in regional science. IZA Discussing Paper No. 10329.

SILVA, J. S. \& TENREYRO, S. (2006). The log of gravity. The Review of Economics and Statistics, Vol 88 (4), 641-658.

SILVA, J. S. \& TENREYRO, S. (2011). Further simulation evidence on the performance of the Poisson pseudo-maximum likelihood estimator. Economics Letters, Vol 112 (2), 220-222.

TUNALI, I. (2000). Rationality of migration. International Economic Review, Vol 41 (4), 893-920.

WESTERLUND, J. \& WILHELMSSON, F. (2011). Estimating the gravity model without gravity using panel data. Applied Economics, Vol 43 (6), 641-649.

YÜCEOL, H. (2011). Türkiye'de illerarası işsizlik oranı farklılıkları, göç ve ekonomik kalkınma. Sosyoekonomi, Cilt 15 (15), 30-54.

\section{Summary}

Istanbul, as it was in the past, is still an important magnet for immigrants. However, it is seen that the internal migration to Istanbul has decreased in recent years. Even though the studies show similar economic and social factors-put forth by migration literature are valid for Turkey, there are doubts about whether these factors are being investigated with appropriate techniques. The gravity model is very popular among internal migration researchers. Most of recent studies investigating internal migration in many countries prefer to use the gravity model for very good reason. Poot, et al. (2016) states that the gravity model is a very common approach for understanding migration flows between the two regions. The most important feature of gravity model is its intuitive consistency with migration theories. Also, its ease of estimating in empirical application and the goodness of fit in most applications make it very successful (Poot, et al., 2016). In studies on immigration in Turkey, it is seen that the OLS method is generally used in estimation of gravity model. But the logarithmic transformation of the gravity model contains some problems. In the presence of heteroscedasticity, the expected value of logarithmic error term will be correlated with other explanatory variables. This causes the OLS estimators to be biased and inconsistent. Another problem is the zero-value migration flow between the two regions. Because of the fact that logarithms of these observations cannot be defined, logarithmic transformation will be improper in this case. Many approaches have been developed to solve this problem. The most common approaches are to add a small positive value all zero-valued observations or get rid of the zero-valued observation by deleting them (Babkova, 2008, s.18). However, it is stated by Flowerdew and Aitkin (1982), Eichengreen and Irwin (1996) and Burger, Van Oord and Linders (2009) that these suggestions are not sufficient to solve the problems. Silva and Tenreyro (2006) indicate that the OLS estimation based on logarithmic transformation is inconsistent in the presence of heteroscedasticity. They recommend using the Poisson pseudo-maximum likelihood estimator to estimate the gravity model. The aim of this study, unlike other studies in the literature, is to investigate internal migration to Istanbul by using the Poisson Pseudo Maximum Likelihood (PPML) estimator, which provides consistent estimation of the gravity model, besides other alternative Poisson panel estimator and is to specify the most appropriate model by testing several alternative panel models. Therefore, we estimated pooled, fixed and random effects models by using two alternative estimators, standard and Poisson. Ramsey's Reset (Regression Equation Specification Error) test is used to compare correct specification of the models. Also, 
goodness-of-fit statistics were calculated for predicted immigration. Hausman specification test was performed to test the assumptions on consistency of RE estimator. The gravity model in this study was set up to investigate the internal migration from 80 provinces in Turkey to Istanbul. As stated in most studies in the literature, our gravity model is formed as a function of the flow of migrants between the two regions, the population of these two regions, the distance between the two regions, the number of migrants in the previous years between the two regions and the difference in unemployment or wage rates between the two regions. When the alternative estimators were compared with the help of the tests, it was found that the most suitable estimator for our model was PPML. Findings from the PPML estimator show that the determinants of internal migration to Istanbul are economic and social factors that have been proven by the other studies in the literature, i.e., the increase in the population, the high level of migration in the past, increase the number of immigrants, and the increase in the distance decreases the internal migration. On the other hand, it was found that relative unemployment rate positively influenced internal migration to Istanbul, but this effect did not statistically significant, unlike most studies in the literature. This result indicates that the increase in the unemployment rate in the provinces does not affect immigration flow to Istanbul and that unemployed persons may have adapted to this situation by leaving the labor force. Unemployed individuals who prefer not to migrate may prefer to stay in their own provinces due to such reasons as receiving unemployment insurance benefits or staying close to the family in order to receive economic support from them. However, these findings need to be supported by further research. 